\title{
THE DEPRESSED TEXT: THE NARRATIVES OF DAVID FOSTER WALLACE AND UNDERSTANDING DEPRESSION BEYOND ITS DESCRIPTIVE CRITERIA
}

\author{
Authors: D.A.H. Ortega Dos Santos (1), C.R. Dantas (1), C.E.M. Banzato (1). \\ (1) University of Campinas (Unicamp), Department of Psychiatry - Medical School, Campinas, Brazil.
}

\section{Keywords: Art, Empathy, David Foster Wallace, Depressive disorders}

- How the teaching and the understanding of certain psychiatric phenomena, particularly subjective ones, could be achieved by means other than general diagnostic criteria? Could diagnostic formulations in psychiatry benefit from something other than objective descriptions of phenomena?

- The North American writer David Foster Wallace, who committed suicide in 2008, was a renowned innovator in literary fiction due to his unique narrative style and to his interest in empathy and communicability. Suffering from severe major depression himself, the author wrote two short stories that illustrate the disorder. Set apart 15 years from one another, they take completely different (and complementary) perspectives on the subject.

- By analyzing two short stories by David Foster Wallace on depression, having in mind not only general criteria and objective descriptions of depression, but also narrative techniques, it is possible to elicit other aspects of the experience of being depressed.

- Whereas the first text is clear in describing objectively depression, the second one is marked by the impossibility of doing so, focusing on narrative techniques that create in the reader distressing subjective experiences, possibly resembling those felt by patients such as distorted time perception, rumination and struggle to mentalize.

- Depression is a common mental disorder that can be difficult to understand and to cope with, not only for patients but also for patient's relatives and even clinicians. Thus, fostering an empathic relation with the patient may prove decisive for an effective treatment. We suggest that literature might be helpful in allowing clinicians to train the skills required for that, broadening their understanding of the experience of being mentally ill.

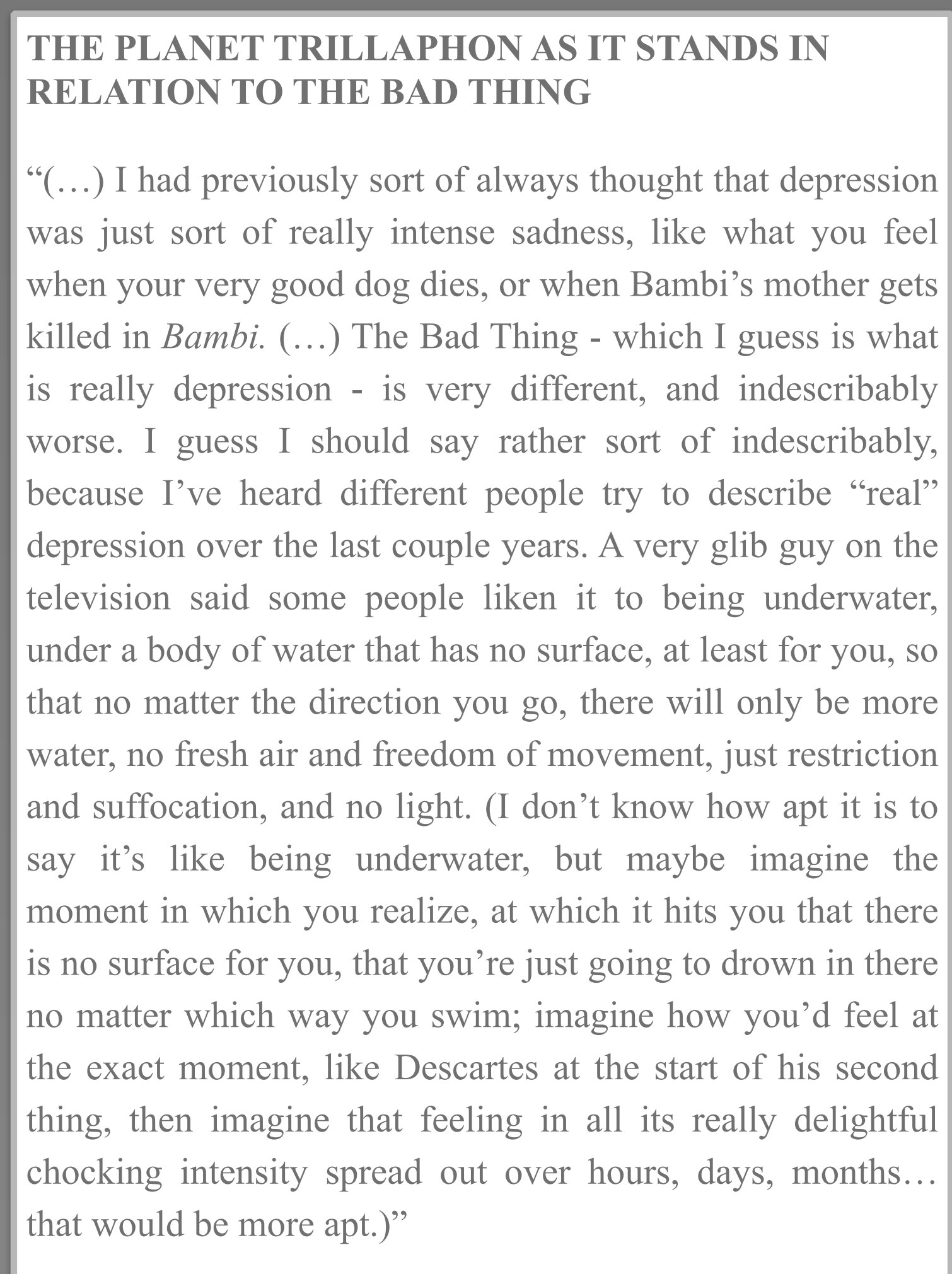

\section{THE DEPRESSED PERSON}

"The depressed person was in terrible and unceasing emotional pain, and the impossibility of sharing or articulating this pain was itself a component of the pain and a contributing factor in its essential horror.

Despairing, then, of describing the emotional pain itself, the depressed person hoped at least to be able to express something of its context - its shape and texture, as it were by recounting circumstances related to its etiology."

References:

- Wallace, D. F. (2000). Brief interviews with hideous men. New York, NY: Little, Brown and Company.

- Wallace, D. F. (2015). The David Foster Wallace reader. New York, NY: Back Bay Books, Little, Brown and Company.

- Serpa, O. D., Leal, E. M., \& Muñoz, N. M. (2019). The Centrality of Narratives in the Mental Health Clinic, Care and Research. Philosophy, Psychiatry, \& Psychology, 26(2), 155-164. doi:10.1353/ppp.2019.0021

- Thornton, T. (2007). Should comprehensive diagnosis include idiographic understanding? Medicine, Health Care and Philosophy, 11(3), 293-302. doi:10.1007/ s11019-007-9117-8

Conflicts of Interest: None

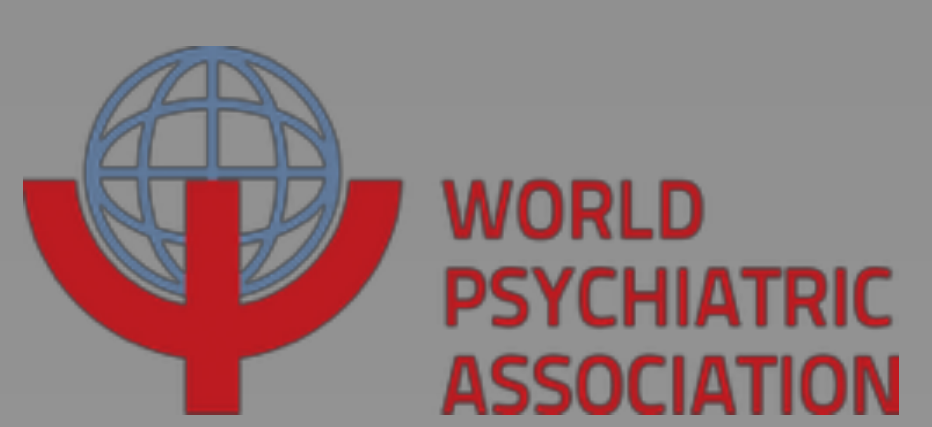

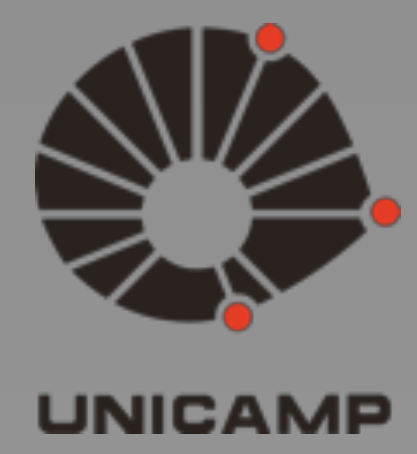

Copyright (C Diego Andre Hortencio Ortega dos Santos, 2019
PSYCHIATRY AND MENTAL HEALTH: GLOBAL INSPIRATIONS, LOCALLY RELEVANT ACTION 